\title{
National Sky Fest in Turkey
}

\author{
Süleyman Fişek ${ }^{* 1,2,3}$ and Sinan Aliş̧ ${ }^{1,2,3}$ \\ ${ }^{1}$ Department of Astronomy and Space Sciences, Faculty of Science, Istanbul University, Istanbul, Turkey \\ ${ }^{2}$ Istanbul University Observatory Research and Application Center, Istanbul, Turkey \\ ${ }^{3}$ Turkish Astronomical Society (TAD)
}

\begin{abstract}
In this paper, TÜBİTAK ${ }^{1}$ National Sky Fest which is held annually in Turkey is presented. In 2019, approximately 1000 people attended to the sky fest. This event has been organized since 1998 with an approximate participants of 400 each year. There are several activities in the festival which span the three days both in daytime and in night programs. TÜBİTAK is planning to organize the event internationally for 2020 .
\end{abstract}

Keywords: public outreach - sky fest - star party - amateur astronomy

\section{Introduction}

In Turkey, there are many astronomy public education and outreach activities organized by astronomy and related departments (Alis, 2018). Among these events, TÜBİTAK National Sky Fest is a special one because it brings people enthusiastic about astronomy together from all over the country.

The first sky fest was organized in 1998 by the TÜBİTAK Science and Technics Magazine ${ }^{2}$ and since 1998, every summer the sky fest has been organized by the team there. Since 2009, the event is carried out by TÜBİTAK National Observatory ${ }^{3}$.

The aim of the sky fest is to give fundamental knowledge about astronomy and introducing night sky to the participants. Also, the most important part of the sky fest is to provide telescope viewing experience guided by the expert astronomers in such a dark place.

\section{Location}

The sky fest takes place in a ski center at the outskirts of Mount Bakirli, Antalya where TUG is located (Figure 1). There is almost no light pollution and the location is suitable for camping and related activities. Daytime and nighttime views of the camping area are shown in Figure 2.

\section{Participation and Participants}

The sky fest is free and open to participation of everyone. The only restriction is that the minors can only participate with their family members. Each year roughly 400 people participate to the festival and this has been the case until 2019. In 2019, more than 6000 people applied to participate the sky fest and approximately 1000 people were allowed to participate. In average, there are always 10 times more application than the capacity of the festival. Therefore, for many years the selection of participants is done under an official overview by a notary and the selection is broadcasted online.

\footnotetext{
*sfisek@istanbul.edu.tr

${ }^{1}$ The Scientific and Technological Research Council of Turkey (tubitak.gov.tr/en)

${ }^{2}$ https://bilimteknik.tubitak.gov.tr

${ }^{3}$ TÜBITAK National Observatory(tug.tubitak.gov.tr/en)
} 


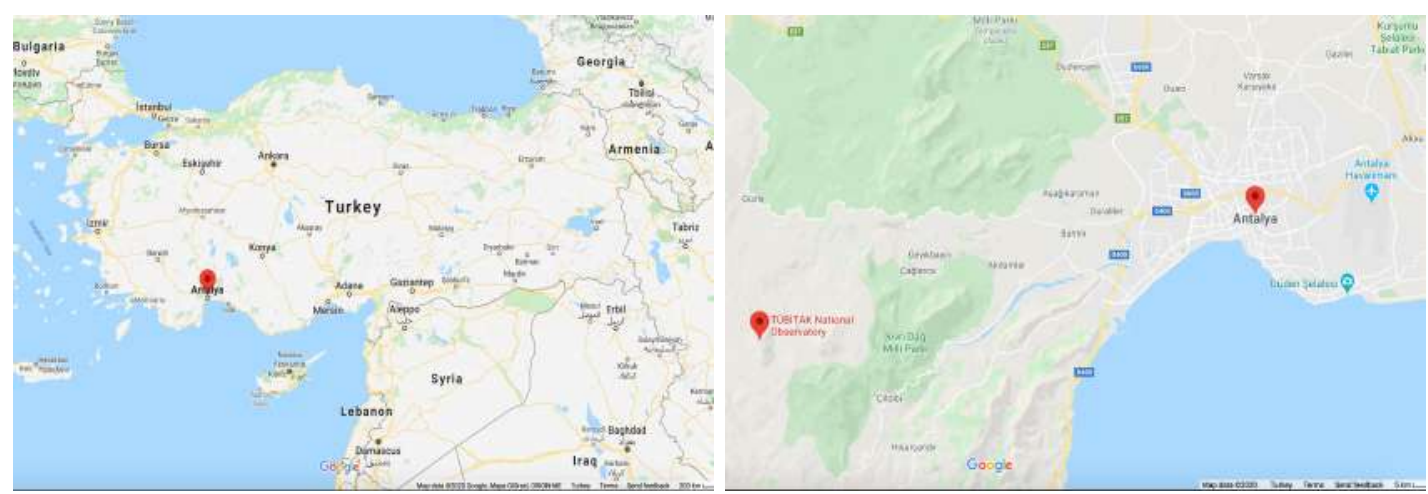

Figure 1. (a)Antalya's location on the map of Turkey. (b) TÜBİTAK National Observatory's location on the map of Antalya. The distance from city center is about $65 \mathrm{~km}$ and 1 hour driving distance.
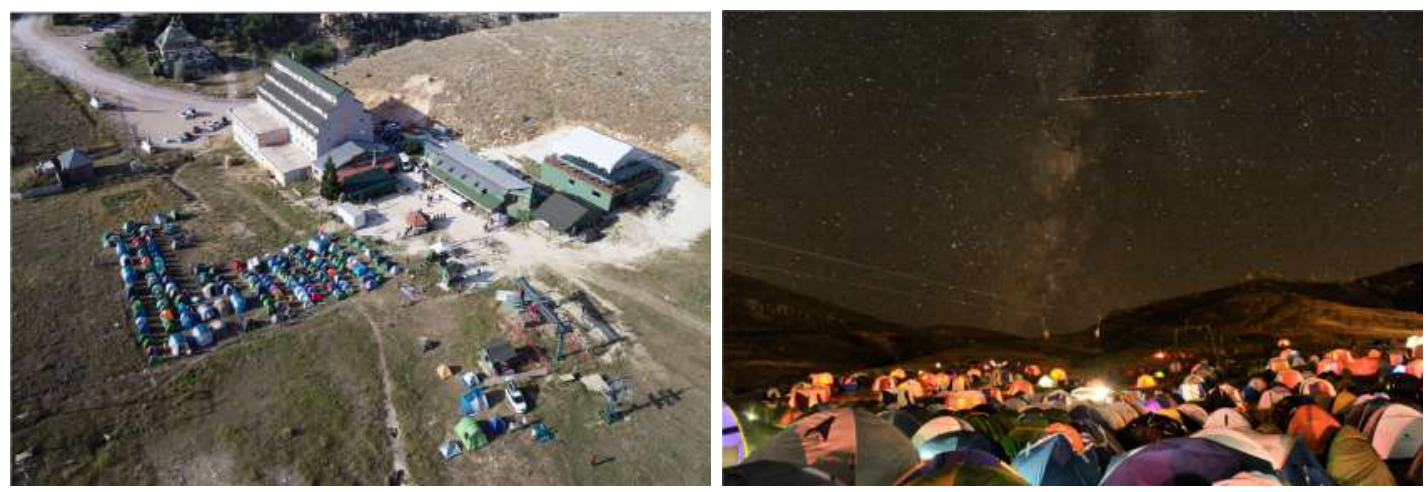

Figure 2. (a)The ski center and camping area in daytime. (b) Camping area in night.

In order to be in the selection process, people who want to participate to the event should apply either individually or as a family from the sky fest website (senlik.tug.tubitak.gov.tr). The website contains all information regarding the event and photos and videos from the previous festivals.

The transportation of participants from Antalya city center to the event area and their food and beverage (water, coffee, tea, etc.) supplies are free of charge during the event. Participants stay in their own tents. In addition, each participant receives an amenity kit (thermal mug, shoulder blanket, sky atlas, cap, etc.) that they can use during the festival. Also, fully equipped ambulance, healthcare professionals and security guards work throughout the event.

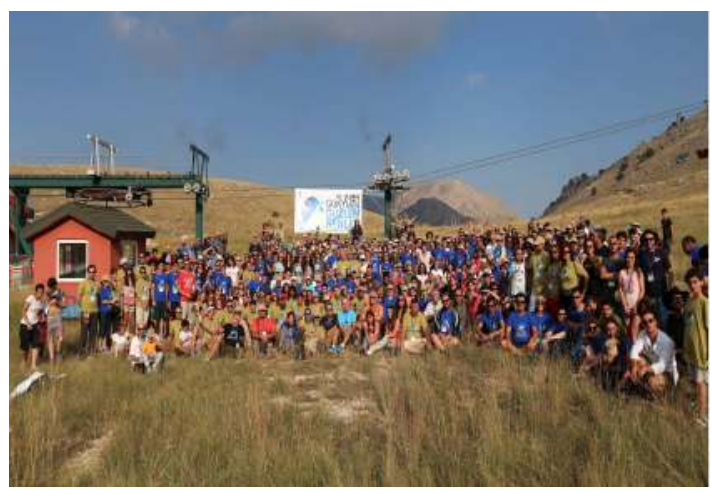

Figure 3. (a)Group photo in 2015. (b) Group photo in 2019.

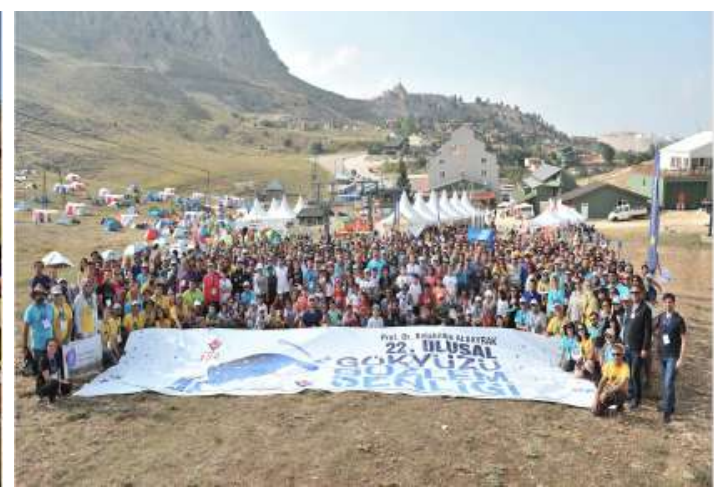



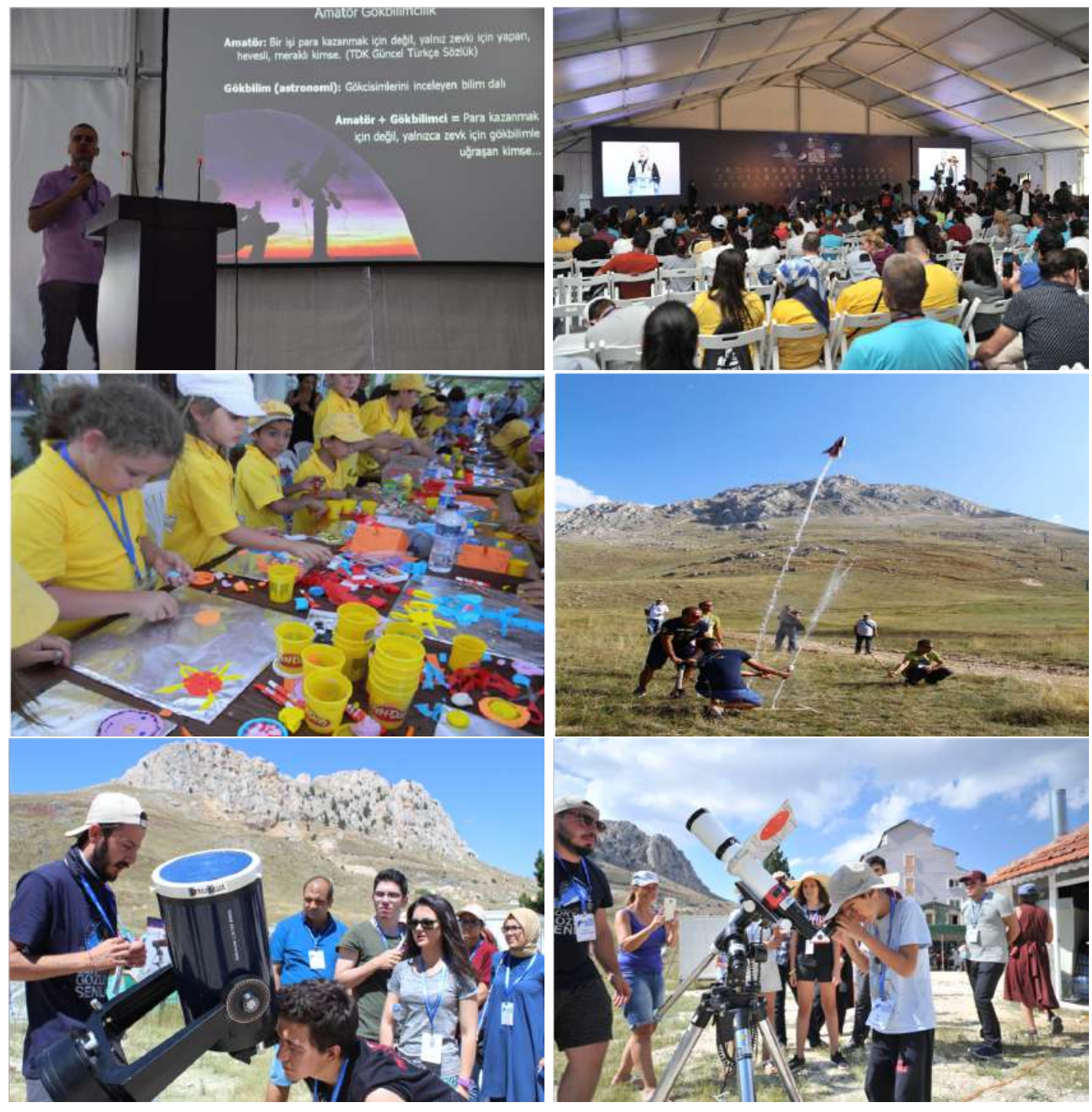

Figure 4. A collage of photos from daytime activities.

\section{Program}

The event program is divided into two as daytime and night programs. Some examples from the daytime program are shown in Figure 4 whereas some scenes of the night program are shown in Figure 5 .

A group of university students works with the TÜBİTAK staff during the event as an organization team. These people are mostly selected from students studying in astronomy departments and they are acting as the instructors and responsible for almost all activities.

\subsection{Daytime}

The daytime program of the event includes popular astronomy talks given by university professors, hands-on activities (mostly for children) and solar observation. In addition, amateur astronomy clubs from all around Turkey have their own stands and interact with participants during the daytime program. Additionally, telescope brands are also represented by the corresponding distributors.

\subsection{Night}

During the night program, participants observe planets, deep-sky objects via telescopes guided by the team of astronomers. During this telescope viewing sessions, team introduce night sky to the participants, explain some phenomena, and answer questions from them. Mostly these sessions 

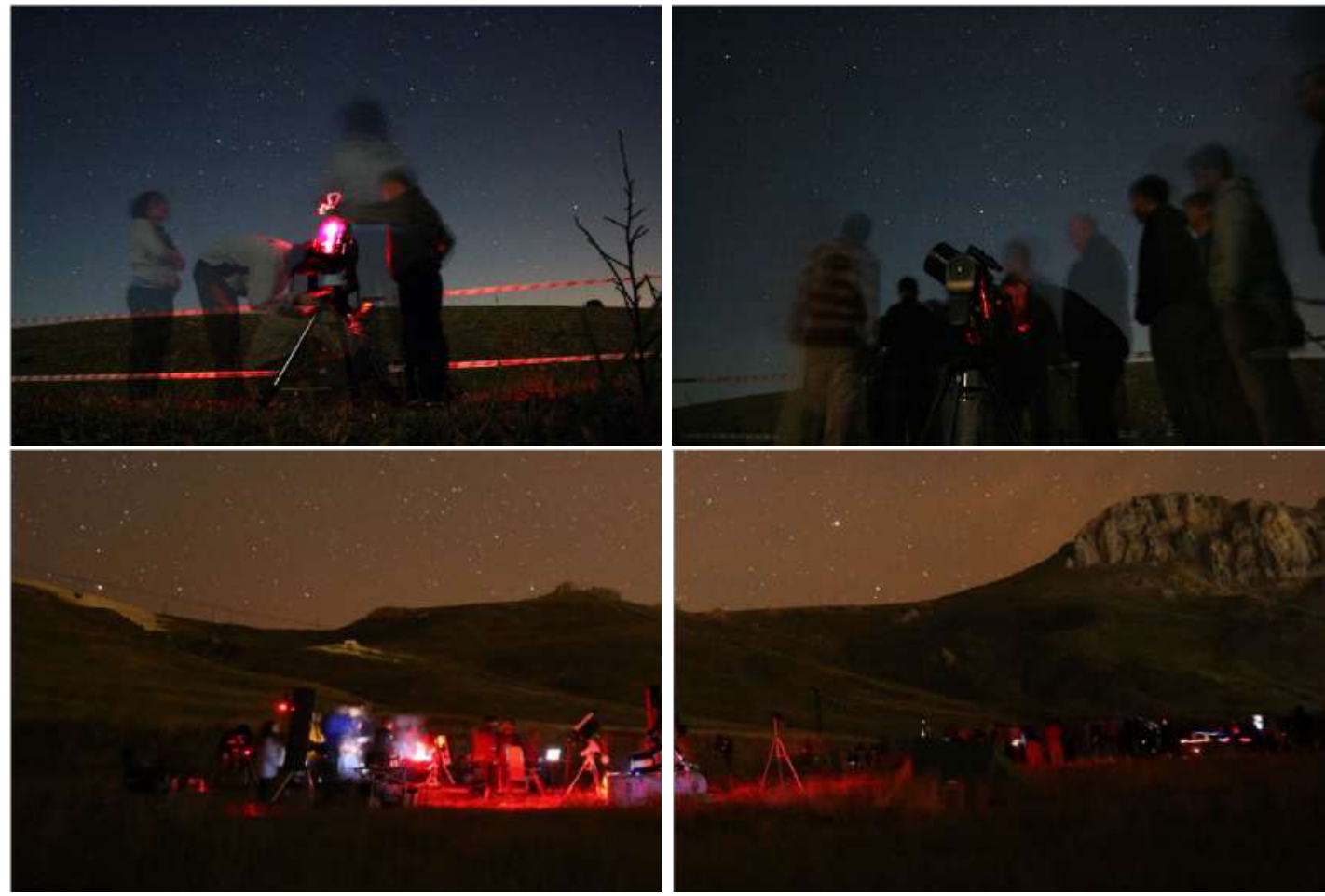

Figure 5. A collage of photos from night activities.

continue until $4 \mathrm{AM}$ in the morning. Depending on the weather the session can be ended earlier, especially due to cloud coverage, humidity or cold.

In order to provide a dark sky to the participants, TÜBİTAK chooses the dates for the sky fest when the Moon rises late, towards early morning. Observing session starts with planets and the objects near the horizon. After a short break for the session, the team introduces the sky for participants and gives information about objects on the sky that can be observed with the naked eye.

A list of objects ordered by their setting times is followed by the astronomer team whose are responsible for the telescopes. Depending on the aperture size, telescope may have slightly different observing plan. Specifically, two of the telescopes follow an observation program like a demonstration of the "Stellar Evolution" which is also mentioned in the daytime program. First, participants observe star formation regions like the Eagle Nebula (M16) and then they observe open clusters like the Ptolemy (M7) for "baby" stars, middle-age stars like Altair and Arcturus, "old" stars like Antares respectively and they finish the sequence by observing planetary nebula (the Ring Nebula, etc.), supernova remnants (the Veil Nebula, etc.) and black holes (GRS 1915-105, Cygnus X-1, etc.).

Moreover, astrophotographers and astrophotograph groups whose are famous nationwide have their own area to take sky/deep-sky photos during the night. They give some information to the participants who is interested in astrophotography such as what is the best equipment for astrophotography, how they can take an image from the sky and processes the image. Two sample photographs that were taken during the sky fest shown in Figure 6.

\section{Summary}

More than 6000 people applied to the sky fest held in 2019, and 1000 of them were allowed to participate the sky fest ${ }^{4}$. This year, more than 11000 people applied to the sky fest which will held in 2020 and 1000 of them will be allowed. As is often the case, the applicants are mostly students (4684) and teachers (1760) in this year and also, most applicants have Bachelor's degrees. Distributions of the education level of the applicants are as follows: $11.6 \%$ of applicants have Master degree, $42.5 \%$ of applicants have Bachelor's degree, $14.6 \%$ of applicants are high school graduate, $7.4 \%$ of applicants

\footnotetext{
${ }^{4}$ http: //senlik.tug.tubitak.gov .tr/?page_id=2413
} 

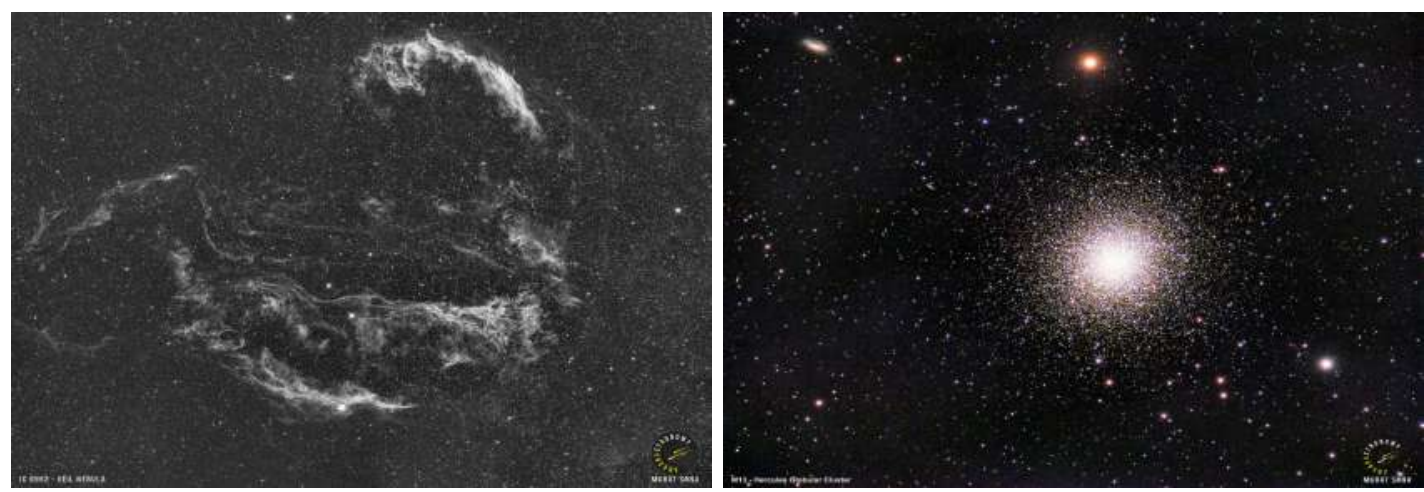

Figure 6. Veil Nebula was taken at the sky fest in 2019 (left) and Hercules Globular Cluster was taken at the sky fest in 2016 (right). Both photos are courtesy of Murat Sana.

are Secondary School graduate, $8.7 \%$ of applicants are Primary School graduate, $4.9 \%$ of applicants have Associate degree, $4.3 \%$ of applicants have Doctor's degree, $4.1 \%$ of applicants are students of the Pre-school education, $1.9 \%$ of applicants are students of the kindergarten class. The ratio of men $(47.9 \%)$ and women $(52.1 \%)$ is almost equal among the applicants.

Although, Antalya is an appropriate city/region for summer holidays, the conditions at the event location can be quite challenging even in summer. Camping in the nature for 3 days under a thinner atmosphere at 2000 meters above the sea-level scorches when it is sunny. Some cold nights happen when you need to wear protective garments. Despite these conditions, those who are willing to participate to the sky fest play an important role for achieving the purpose of the event. The busy schedule of the sky fest is enjoyable and beneficial instead of being bored especially for enthusiastic participants. Those people, when they gain enough experience in the sky fest can lead for other outreach activities afterwards.

Nowadays, there are many similar events held in Turkey but TÜBİTAK (Inter)National Sky Fest continues to be the most special one. Interest from the public to the similar events is increased every day. There are programs from TÜBİTAK that give support with substantial grants which organizations like universities, municipalities and science centers can apply and with the help of that grant they can organize similar events locally throughout the country.

\section{Acknowledgements}

Authors are grateful for the hospitality of the Byurakan Astrophysical Observatory staff. Authors acknowledge the support from the IAU South West and Central Asia Regional Office of Astronomy for Development. As part of the sky fest team, authors are also grateful for everyone in the team as well as TÜBITAK National Observatory (TUG) staff that made this event possible.

\section{References}

Alis S., 2018, Communications of the Byurakan Astrophysical Observatory, 65, 144 